\title{
ENERGY-FILTERED IMAGING OF PRECIPITATES IN FeCUN ALLOYS
}

\author{
P. M. Rice, R. E. Stoller, and J. Bentley \\ Metals and Ceramics Division, Oak Ridge National Laboratory, P.O. Box 2008, \\ Oak Ridge, TN 37831-6376
}

The microstructures of a series of model ferritic alloys are being characterized by transmission electron microscopy (TEM) techniques. The alloys have varying concentrations of $\mathrm{Cu}(0$ to $0.9 \mathrm{wt} \%), \mathrm{N}$ ( 5 to 120 appm), and other solutes to allow a systematic study of the effects of various elements on embrittlement. The first step in this process is the characterization of the alloys in their as-received state: solution treated at $775^{\circ} \mathrm{C}$ for $17 \mathrm{~h}$, quenched in a salt bath at $450^{\circ} \mathrm{C}$ for $180 \mathrm{~s}$, and subsequently air cooled.

The imaging portion of this initial study is complete; however, several questions about the chemical content of many of the precipitates remain unanswered. The heat treatment described above resulted in extensive precipitation, especially in the high $\mathbf{N}$ alloys. It is difficult to distinguish between $\alpha^{\prime \prime}$ nitride platelets and the $\varepsilon$-carbide platelets which formed in many of the alloys. High-angle tilting is difficult with these ferromagnetic specimens, and the $\mathbf{g} \cdot \mathbf{R}=0$ invisibility criterion previously used for distinguishing the $\alpha^{\prime \prime}$ nitrides 1 has given ambiguous results. It is necessary to use analytical methods to determine the chemical content of the platelets. To this end, energy-filtered imaging is being used to identify these and other precipitates in these alloys. A Gatan Imaging Filter (GIF), installed on a Philips CM30 operated at $300 \mathrm{kV}$, was used. Figure 1(a) shows a conventional TEM image of a 0.17 wt\% carbon alloy with $\mathbf{g}=$ 011 and beam direction near [100] $\alpha$; a large edge-on (010) platelet runs diagonally across the image. Figure 1(b) shows the C elemental map of the same platelet acquired with a $30 \mathrm{eV}$ window centered at 298 $\mathrm{eV}$ and with the background calculated from two pre-edge, $30 \mathrm{eV}$ windows centered at $217 \mathrm{eV}$ and $258 \mathrm{eV}$. The image clearly shows that the platelet contains $\mathrm{C}$, identifying it as an $\varepsilon$-carbide, as well as the fact that the platelet apparently formed on or near a spherical carbon-containing precipitate.

To study the affect of $\mathrm{Cu}$ precipitation on the hardening of the alloys, a $0.9 \mathrm{wt} \% \mathrm{Cu}$ alloy was annealed at $550^{\circ} \mathrm{C}$ for times up to $15 \mathrm{~h}$. The Cu precipitates that form undergo a phase change from bcc to a faulted fcc (9R) crystal structure when they are about $6 \mathrm{~nm}$ in diameter. 2 These fcc precipitates have been well characterized by conventional TEM techniques for these alloys. However, the smaller bcc $\mathrm{Cu}$ precipitates are difficult to image in these strongly oxidation-prone specimens. Energy-filtered imaging is being evaluated as a possible technique to image and measure the size distribution of the small Cu precipitates. Figure 2 shows examples of energy-filtered images from an annealed $.9 \mathrm{wt} \% \mathrm{Cu}$ alloy. Figure 2(a) shows the Fe jump-ratio image calculated by dividing an image acquired with a $30 \mathrm{eV}$ post-edge window centered at $725 \mathrm{eV}$ by an image acquired with a $30 \mathrm{eV}$ pre-edge window centered at $685 \mathrm{eV}$. Figure 2(b) shows the $\mathrm{Cu}$ jump-ratio image for the same region with images acquired at $948 \mathrm{eV}$ and $908 \mathrm{eV}$. Black arrows mark the same precipitates in (a) and (b) clearly showing that the $\mathrm{Cu}$ precipitates appear as a lack of signal in the $\mathrm{Fe}$ image. These preliminary results are very promising, and the search for smaller $\mathrm{Cu}$ precipitates is in progress. 3

\section{References}

1. K.F.Hale and D. McLean, J. of Iron and Steel Institute, (1963) 337.

2. P. J. Othens et. al., Phil. Mag. Lett. 64(1991)383.

3. This research is sponsored by the Division of Materials Sciences, U.S. Dept. of Energy and the Office of Nuclear Regulatory Research, U.S. Nuclear Regulatory Commission under interagency agreement DOE 1886-8109-8L with the U.S. Dept. of Energy under contract DE-AC05-840R21400 with Martin Marietta Energy Systems Inc. and by an appointment of P. M. Rice to the ORNL Postdoctoral Research Associates Program administered jointly by ORNL and Oak Ridge Institute for Science and Education. 


\section{DISCLAIMER}

Portions of this document may be illegible in electronic image products. Images are produced from the best available original document. 


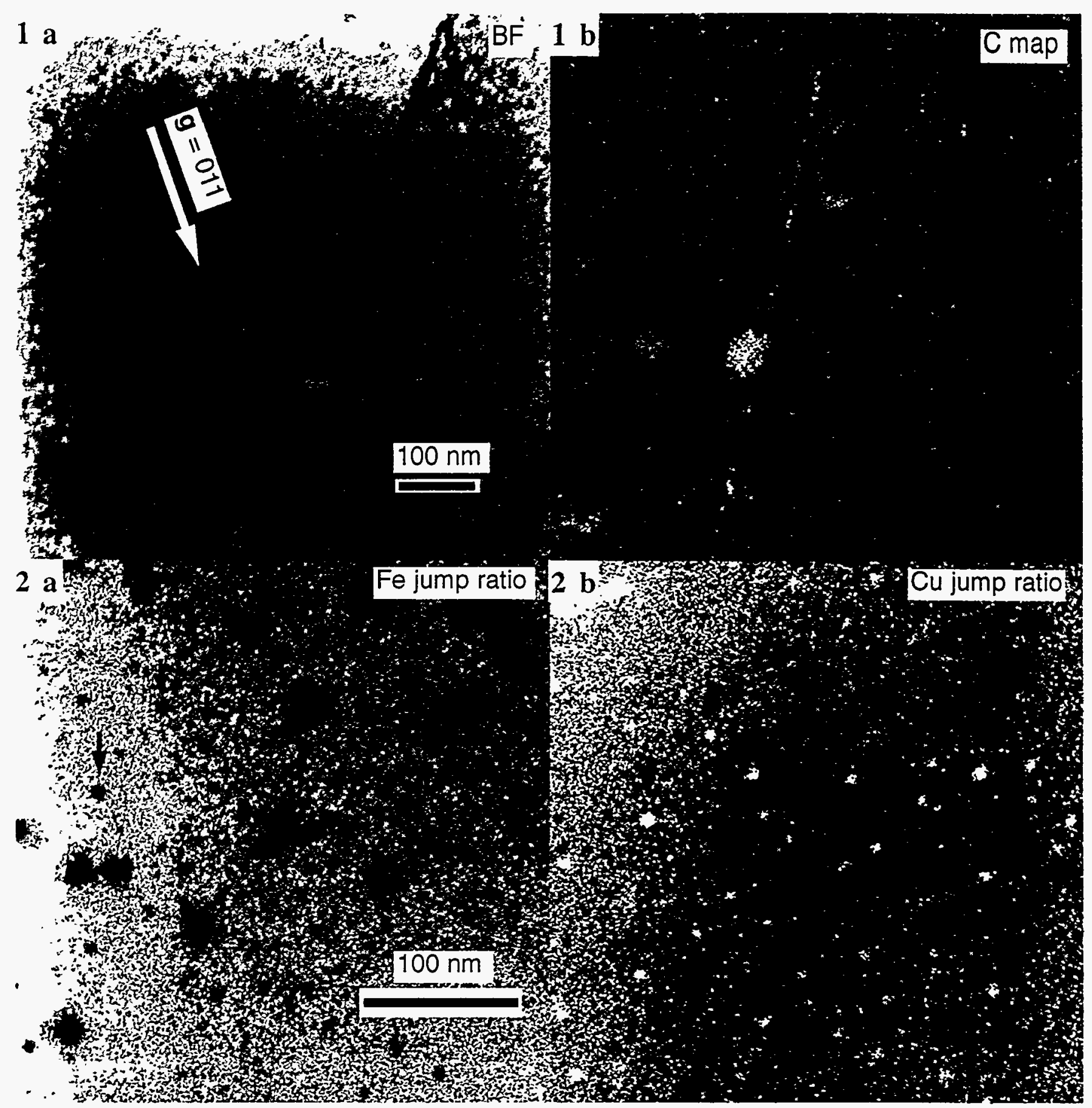

Fig. 1.- Edge-on platelet which precipitated in a high-C $(0.17 \mathrm{wt} \%)$ alloy.

(a) Conventional TEM image with $\mathbf{g}=011$ (white arrow) and beam direction near $[100]_{\alpha}$.

(b) Carbon elemental map calculated from energy-filtered images recorded with $30 \mathrm{eV}$ pre-edge windows centered at $217 \mathrm{eV}$ and $258 \mathrm{eV}$, and a $30 \mathrm{eV}$ post-edge window centered at $298 \mathrm{eV}$.

Fig. 2.- Fcc $\mathrm{Cu}$ precipitates in an annealed high- $\mathrm{Cu}(0.9 \mathrm{wt} \%)$ alloy. The black arrows point the same precipitates in both (a) and (b).

(a) Fe jump-ratio image calculated by dividing an energy-filtered image acquired with a $30 \mathrm{eV}$ post-edge window centered at $725 \mathrm{eV}$ by a pre-edge image centered at $685 \mathrm{eV}$.

(b) $\mathrm{Cu}$ jump-ratio image of the same region calculated by ratioing images acquired with $30 \mathrm{eV}$ post-edge and $30 \mathrm{eV}$ pre-edge windows centered at $948 \mathrm{eV}$ and $908 \mathrm{eV}$, respectively. 


\section{DISCLAIMER}

This report was prepared as an account of work sponsored by an agency of the United States Government. Neither the United States Government nor any agency thereof, nor any of their employees, makes any warranty, express or implied, or assumes any legal liability or responsibility for the accuracy, completeness, or usefulness of any information, apparatus, product, or process disclosed, or represents that its use would not infringe privately owned rights. Reference herein to any specific commercial product, process, or service by trade name, trademark, manufacturer, or otherwise does not necessarily constitute or imply its endorsement, recommendation, or favoring by the United States Government or any agency thereof. The views and opinions of authors expressed herein do not necessarily state or reflect those of the United States Government or any agency thereof. 